\title{
Impact of an Educational Program about Cancer Pain Management on Nurses' Knowledge, Attitudes, and Practice at Intensive Care Unit
}

\author{
Bander A Musleh, Samy A Erfan, Mona A Mohammed \& Mervat A Abd-EIAziz \\ Clinical Nurse Specialist in National Oncology Center Sana'a- Yemen. \\ Professor of Anesthesia and ICU, South Egypt Cancer Institute, Assiut University, Egypt. \\ Lecturer of critical care nursing. Faculty of nursing, Assiut University, Egypt. \\ Lecturer of critical care nursing, Faculty of nursing, Assiut University, Egypt.
}

\begin{abstract}
Background: cancer pain has emerged as a leading stressor for patients with cancer in the intensive care unit (ICU).Unrelieved pain gives rise to negative physiologic and psychological events that can be detrimental to critically ill patients' health outcomes Aim of the study: evaluate the impact of an educational program about cancer pain management on nurses' knowledge, attitudes and practice at intensive care unit. Subject and methods: Quasi-experimental design was utilized in this study. A convenience sample of 55 ICU nurses 30 were nursing diploma, 17 were technical degree and 8 bachelor degree. The data were collected using the tool I Pre/post-test nurses' knowledge and attitudes assessment questionnaire sheet for assessment of nurses' knowledge and attitudes, tool II pre/post observation checklist to assess nurse practices. Results: The result reveals that the majority of nurses had unsatisfactory of knowledge and negative attitudes regarding cancer pain management pre-education program. The mean scores were improved significantly $(\mathrm{P}=0.001)$ post education program, also, the majority of nurse's practice were an inadequate pre-education program; they improved significantly $(\mathrm{P}=0.001)$ post education program. Conclusion: The study concluded that the education program leads to significant improvement in nurse's knowledge attitudes and practices about cancer pain management.
\end{abstract}

\section{Key Words: Educational Program, Cancer Pain, Management, Nurses \& Intensive Care Unit.}

\section{Introduction}

Pain is a common feature for patients with a cancer disease. Frequent or persistent experiences of pain and discomfort affect most aspects of a patient's life, physical functioning, daily activity, psychological and emotional status and social life. Uncontrolled pain not only leads to discomfort and suffering but can also have unwanted consequences such as delayed healing, an increased risk of morbidity, a prolonged hospital stay, and the risk of developing chronic persistent pain. Even though cancer-related pain frequently becomes long lasting, the importance of accurate pain management of the phases is most urgent. (Elumelu et al., 2014)

cancer pain is a common occurrence during an ICU stay due to invasive procedures, surgical procedures, disease processes, medical treatments, and most commonly due to everyday care and treatment by nurses, therefore effective treatment of pain is a key responsibility of the critical care nurses, for this reason, an educational program for ICU nurses caring for cancer patient is essential to bring about the best results for the patient. (Borglin et al., 2011) There are many classifications of pain. The first classification categories pain according to the underlying pathophysiology as nociceptive or neuropathic pain, the second categories pain along a continuum of duration, into acute and chronic pain. Chronic pain is further classified as malignant chronic pain and non-malignant chronic pain (Turk \& Okifuji, 2010).

Postoperative pain is known to be predominantly neuropathic in character, whereby neuropathic pain is defined as 'pain caused by a lesion or disease of the somatosensory system. Postoperative pain is an expected result of a surgical procedure and is an undesirable Sensory and affective experience related to tissue trauma or disease processes (Abdalrahim et al, 2011)

Despite the success of the WHO analgesic ladder, much cancer pain remains uncontrolled. The prevalence of undertreatment of pain has been found to be as much as $43 \%$. There are many barriers to effective pain control, and these include a lack of national policies and low priority assigned to pain relief; a lack of national standards and guidelines for providing pain control medications; legal restrictions on the importation and medical use of opioids; the greatly exaggerated concern that the use of opioids will lead to drug abuse and addiction. (Namukwaya et al., 2011)

The nurse helps relieve pain by administering painrelieving interventions (including both 
pharmacological and non-pharmacological approaches), assessing the effectiveness of those interventions, monitoring for adverse effects, and serving as an advocate for the patient when the prescribed intervention is ineffective in relieving pain. In addition, the nurse provides education to the patient and family to enable them to manage the prescribed intervention themselves when appropriate. (Smeltzer et al., 2012)

Research into nurses' knowledge and attitudes regarding pain management continues to show inadequate levels of knowledge and inappropriate attitudes. Prominently reported knowledge deficit areas include issues related to pain physiology, pharmacology of analgesic drugs and risks associated with opioid drugs. Prominently reported negative attitudes and misconceptions are, patient pain assessment related; and, opioid-related, i.e. inaccurate beliefs about tolerance and addiction (Jastrzab et al., 2004)

Knowledge, attitudes and practice of pain management and its treatment can be improved by means of educational interventions and this will also contribute to eliminating the barriers to pain management. The overall goal of the educational intervention was to inform nurses and enable them to become more active pain managers in providing optimal care to their patients. (Mathew et al., 2011)

\section{Significance of the study}

This study is significant as no other studies have been conducted in South Egypt Cancer Institute in Assiut University to determine the nurses' knowledge, attitudes and practice regarding cancer pain management.

\section{Aims of the study}

The aim of this study was to evaluate the impact of an educational program about cancer pain management on nurses' knowledge, attitudes and practice at intensive care unit.

\section{Research Hypothesis}

To fulfill the aim of this study, the following research hypotheses were formulated:

1. The post mean knowledge and attitudes scores of nurses will be higher than pre mean knowledge and attitudes scores.

2. The post-practice score of nurses will be higher than the pre mean practice scores.

\section{Subjects \& Methods}

Research design:

Quasi-experimental (one-group pretest/posttest design) was utilized for implementation in this study.

\section{Setting}

The study was conducted in the intensive care unit of South Egypt Cancer Institute at Assiut University. Sample

Convenient samples of 55 nurses recruited from the intensive care unit were invited to participate in this study.

Tools of the study

Data pertinent to the study were collected, utilizing the following two tools.

Tool I: Pre/post-test nurses' knowledge and attitudes assessment questionnaire sheet:

This tool was adopted from Nurses' Knowledge and Attitudes Survey Regarding Pain. It was used to assess nurses' knowledge and attitudes of about cancer pain management before and immediately after implementation of education program about cancer pain management, it consists of two main parts:

\section{Part I: Socio-demographic data:}

It is concerned with socio-demographic characteristics of the nurses such as age, sex, level of nursing education, years of nursing experience in intensive care unit and previously attended education program about pain management.

Part II: Nurses' knowledge and attitudes survey regarding pain (NKASRP)

This part was used to assess nurses` knowledge and attitudes about cancer pain management. It consists of 37 questions that covered aspects of pain assessment, patient variables, pharmacologic and non-pharmacologic interventions. Three types of questions were used It includes 21 true/false questions and 14multiple-choice questions. The last 2 items contain patient care that allow the nurse to assess the patient's pain level and administer a range of medication based on the assessment. The nurses' knowledge and attitudes survey regarding pain content were based on the American Pain Society, the World Health Organization, and the Agency for Health Care Policy and Research pain management guidelines. (Ferrell \& Mccaffery, 2012)

\section{Scoring system of knowledge}

The total scores of nurses' knowledge are 30 grades, correct responses for the questions were assigned a score of one, incorrect answers or those not answered were assigned a scored as zero. The interpretation of scores was performed according to the following grading criteria, those who obtained $\geq 60$ were considered having satisfactory level, While those who obtained $<60 \%$ were considered having unsatisfactory level

\section{Scoring system of attitudes}

The total scores of nurses' and attitudes are 9 grades, correct responses for the questions were assigned a score of one, incorrect answers or those not answered 
were assigned a scored as zero. The interpretation of scores was performed according to the following grading criteria, those who obtained $\geq 60$ were considered having a positive attitude, While those who obtained $<60 \%$ were considered having a negative attitude.

Tool II: Pre/post an observation checklist sheet Observation checklist was developed by the researcher based on evidence of pain management. It was used before and immediately after implementation of an education program about cancer pain management to assess the impact of the program on nurses' practice. It includes the main observations related to the nursing care given to the cancer patient who has pain.

\section{Scoring system}

The total score of observation checklist was 32 degree; each item in checklist was scored as following: one degree for each step that done and zero for the step that not done. Scoring system translated in results into adequate and inadequate. Scores $\geq 60 \%$ was graded as an adequate level of practice, While Scores $<60$ were graded as inadequate of level practice.

\section{Methods}

- An official permission obtained from authorized administration, faculty of nursing, manager of South Egypt Cancer Institute in Assiut University and the manager of ICU in South Egypt Cancer Institute at Assiut University.

- The tool was developed by the researcher after reviewing the related literature.

- The tools were tested for content related to content clarity, and validity by a jury of five expertise's in the field of critical care nursing and critical care medicine.

- A pilot study was conducted on $10 \%$ of the sample in a selected setting for testing clarity feasibility and applicability of the study tools.

- Permission for voluntary participation was obtained from nurses and the nature and purpose of the study were explained.

\section{Procedure}

The study was executed on three phases; Preparatory phase, implementation phase, and evaluation Phase.

Phase (1): Preparatory phase

- In this phase the researcher designed and tested an educational program after extensive literature review about cancer pain management and assessment of nurses' knowledge, attitudes and nurses' practice in this regard.

- The questionnaire schedule was given to the nurses at the beginning of the implementation of the education program, the result of the sheet was considered as pretest assessment.
- Observation checklist for nurses was applied by the researcher during the morning and afternoon shift.

- Each nurse was observed separately to complete the observation checklist.

- The practice was done before and immediately after implementation of education program

The content of the program covered two parts related to

- Knowledge and attitudes regarding cancer pain management

- Practice of specific procedures required for management of cancer pain

Phase (2): Implementation phase

- The researcher introduced himself to initiate communication, explain the nature and purpose of the study.

- The participants were asked to complete the questionnaire sheet individually to assess nurses' knowledge and attitudes before application of education program.

- The researcher fills out the observation checklist to assess nurses' practice prior to application of pain education program.

- The educational program about cancer pain management was implemented for ICU nurses in the form of scheduled sessions for both theoretical and practical during their official working hours.

- The program was implemented 8 times for the 8 sub-groups of nurses, 3 educational sessions were implemented for each group to cover all information about cancer pain management.

- Each participant obtained a copy of program booklet that included all the educational material.

Each session covered the following topics:

A) Session One

- Introduction about cancer pain

- Definition of pain

- Types of cancer pain

- Causes of cancer pain

B) Session Two

- Assessment of pain

- Type of pain assessment tools

- Pharmacological intervention in management of cancer pain and type of analgesic drugs

- Potential side effect of analgesic drugs

C) Session Three

- Non-pharmacological intervention in management of cancer pain

- Nursing care and the role of the nurse in the treatment of pain for cancer

- Summary for the most significant information that has been extracted from pain assessment questionnaire sheet 


\section{D) Practical session include}

- Interviewing patients regarding the characteristics of pain

- Conducting a physical assessment related to pain

- Developing a plan of care

- Applying nursing care for the patient who has pain efficiently

- monitoring for potential side effects of pharmacologic interventions

- Re-assessing patients after interventions

Phase (3): Evaluation Phase

The evaluation was done immediately after the end of the educational program. The second data collection occurred and the same pre-test study tools were used post tests for studied subjects in order to test the effectiveness of the program on nurse's knowledge, attitudes and practice. The comparison was done before and after program implementation.

\section{Data analysis}

The statistical analysis was carried out using SPSS version 20. The collected data were tabulated and analyzed by using frequency distribution, the percentage for qualitative variables. Mean, range and standard deviation for quantitative variables the level of significance was considered at 5\% level $(\mathrm{P}=0.05)$. Chi-square test was used to determine the differences between qualitative variables and paired t-test was used to determine differences between quantitative variables.

\section{Results}

Table (1): Frequency distribution of Socio-demographic characteristics of intensive care unit nurses. $(\mathrm{No}=55)$.

\begin{tabular}{|c|c|c|}
\hline Characteristics & No. & $\%$ \\
\hline \multicolumn{3}{|l|}{ Age } \\
\hline Range & \multicolumn{2}{|c|}{$20-45$ years } \\
\hline Mean + SD & \multicolumn{2}{|c|}{$26.0+5.2$} \\
\hline 20-30 years & 47 & 85.5 \\
\hline $30-40$ years & 7 & 12.7 \\
\hline More than 40 years & 1 & 1.8 \\
\hline \multicolumn{3}{|l|}{ Sex } \\
\hline Male & 7 & 12.7 \\
\hline Female & 48 & 87.3 \\
\hline \multicolumn{3}{|l|}{ Qualification } \\
\hline Diploma & 30 & 54.5 \\
\hline Technical & 17 & 31.0 \\
\hline Bachelor & 8 & 14.5 \\
\hline \multicolumn{3}{|l|}{ ICU Years of experience } \\
\hline $0-<1$ year & 27 & 49.1 \\
\hline $1-<5$ years & 18 & 32.7 \\
\hline$>=5$ years & 10 & 18.2 \\
\hline \multicolumn{3}{|l|}{ Training about pain management } \\
\hline Yes & 8 & 14.5 \\
\hline No & 47 & 85.5 \\
\hline
\end{tabular}

Table (2): Numbers and percentages of the nurses' knowledge regarding cancer pain management pre and post education program.

\begin{tabular}{|l|c|c|c|c|c|}
\hline \multirow{2}{*}{ Nurses' Knowledge Items } & \multicolumn{2}{c|}{ pre $(\mathbf{n = 5 5})$} & \multicolumn{2}{c|}{ post $(\mathbf{n = 5 5 )}$} & \multirow{2}{*}{ P. Value } \\
\cline { 2 - 5 } & $\mathbf{n o .}$ & $\mathbf{\%}$ & $\mathbf{n o .}$ & $\mathbf{\%}$ & \\
\hline Vital signs are always indicators for pain & $\mathbf{1 6}$ & $\mathbf{2 9 . 1}$ & $\mathbf{5 2}$ & $\mathbf{9 4 . 5}$ & $\mathbf{0 . 0 0 1} * * *$ \\
\hline Children under 2 years have decreased pain sensitivity & $\mathbf{2 3}$ & $\mathbf{4 1 . 8}$ & $\mathbf{4 0}$ & $\mathbf{7 2 . 7}$ & $\mathbf{0 . 0 0 1} * * *$ \\
\hline Patients may sleep in spite of severe pain & $\mathbf{4}$ & $\mathbf{7 . 3}$ & $\mathbf{4 7}$ & $\mathbf{8 5 . 5}$ & $\mathbf{0 . 0 0 1} * * *$ \\
\hline NSAID is not effective analgesic for boney metastasis & $\mathbf{1 3}$ & $\mathbf{2 3 . 6}$ & $\mathbf{4 1}$ & $\mathbf{7 4 . 5}$ & $\mathbf{0 . 0 0 1} * * *$ \\
\hline Combining analgesic works better than a single analgesic & $\mathbf{3 1}$ & $\mathbf{5 6 . 4}$ & $\mathbf{5 4}$ & $\mathbf{9 8 . 2}$ & $\mathbf{0 . 0 0 1} * * *$ \\
\hline duration of analgesia of 1-2 mg morphine IV is 4-5 hours & $\mathbf{2 2}$ & $\mathbf{4 0 . 0}$ & $\mathbf{4 5}$ & $\mathbf{8 1 . 8}$ & $\mathbf{0 . 0 0 1} * * *$ \\
\hline Promethazine and hydroxyzine as potentiates of opioids & $\mathbf{2 4}$ & $\mathbf{4 3 . 6}$ & $\mathbf{4 7}$ & $\mathbf{8 5 . 5}$ & $\mathbf{0 . 0 0 1} * * *$ \\
\hline
\end{tabular}




\begin{tabular}{|c|c|c|c|c|c|}
\hline \multirow{2}{*}{ Nurses' Knowledge Items } & \multicolumn{2}{|c|}{ pre $(n=55)$} & \multicolumn{2}{|c|}{ post $(n=55)$} & \multirow{2}{*}{ P. Value } \\
\hline & no. & $\%$ & no. & $\%$ & \\
\hline Patients' spiritual belief may affect their concept of pain. & 37 & 67.3 & 53 & 96.4 & $0.001 * * *$ \\
\hline Adjust of Subsequent dose of opioid & 36 & 65.5 & 53 & 96.4 & $0.001 * * *$ \\
\hline Equivalent dosage of morphine to Vicodin & 20 & 36.4 & 52 & 94.5 & $\mathbf{0 . 0 0 1} * * *$ \\
\hline Opioids could mask diagnose the cause of pain & 6 & 10.9 & 39 & 70.9 & $\mathbf{0 . 0 0 1} * * *$ \\
\hline Anticonvulsant relieves pain after a single dose & 33 & 60.0 & 55 & 100.0 & $0.001 * * *$ \\
\hline Benzodiazepines are not effective pain relievers & 29 & 52.7 & 49 & 89.1 & $0.001 * * *$ \\
\hline Opioid Addiction is a chronic neurological disease & 45 & 81.8 & 52 & 94.5 & $\mathbf{0 . 0 3 9} *$ \\
\hline Persistent cancer-related pain & 15 & 27.3 & 52 & 94.5 & $0.001 * * *$ \\
\hline Severe pain of sudden onset & 44 & 80.0 & 55 & $\mathbf{1 0 0 . 0}$ & $0.001 * * *$ \\
\hline Prolonged moderate to severe pain for cancer & 28 & 50.9 & 52 & 94.5 & $0.001 * * *$ \\
\hline Intravenous dose Morphine equivalent to oral dose & 20 & 36.4 & 48 & 87.3 & $0.001 * * *$ \\
\hline Frequency of analgesic for post-operative pain. & 23 & 41.8 & 49 & 89.1 & $0.001 * * *$ \\
\hline $\begin{array}{l}\text { Chance of respiratory depression for cancer patients on opioid } \\
\text { analgesics. }\end{array}$ & 15 & 27.3 & 48 & 87.3 & $0.001 * * *$ \\
\hline Reasons for increased doses of pain medications. & 40 & 72.7 & 52 & 94.5 & $0.002 * * *$ \\
\hline Useful type of analgesic for cancer pain & 39 & 70.9 & 48 & 87.3 & $\mathbf{0 . 0 3 5 *}$ \\
\hline Cultural considerations in caring patients in pain. & 18 & 32.7 & 53 & 96.4 & $0.001 * * *$ \\
\hline The time to peak effect for morphine given Intravenous & 50 & 90.9 & 55 & 100.0 & $0.022 *$ \\
\hline The time to peak effect for morphine given orally & 17 & 30.9 & 49 & 89.1 & $\mathbf{0 . 0 0 1} * * *$ \\
\hline Manifestation of discontinuation of an opioid & 10 & 18.2 & 50 & 90.9 & $0.001 * * *$ \\
\hline $\begin{array}{l}\text { Pain assessment in the absence of vital sign and presence of } \\
\text { behavioral changes. }\end{array}$ & 14 & 25.5 & 51 & 92.7 & $0.001 * * *$ \\
\hline $\begin{array}{l}\text { Morphine administration for reported persistent postoperative } \\
\text { pain in the absence of vital sign indicators and side-effects }\end{array}$ & 5 & 9.1 & 45 & 81.8 & $0.001 * * *$ \\
\hline Pain assessment in the absence of vital sign changes & 9 & 16.4 & 48 & 87.3 & $0.001 * * *$ \\
\hline $\begin{array}{l}\text { Morphine administration for reported pain in the absence of } \\
\text { vital sign and presence behavioral indicators }\end{array}$ & 11 & 20.0 & 51 & 92.7 & $0.001 * * *$ \\
\hline $\begin{array}{l}\text { Mean } \pm \text { SD of Total knowledge score } \\
\text { total score }(\text { total }=30)\end{array}$ & \multicolumn{2}{|c|}{$12.7 \pm 3.7$} & \multicolumn{2}{|c|}{$27.0 \pm 3.3$} & $\mathbf{p}<0.001 * * *$ \\
\hline
\end{tabular}

Chi-square test to compare between percentages paired $t$-test to compare between pre and post means

Non-significant $(P>0.05) \quad$ *: Significant $(P<0.05) * *$ : Moderate significant $(P<0.01)$

***: Highly significant $(P<0.001) \quad$ NSAID: Non-Steroidal Anti-Inflammatory Drugs

Table (3): Numbers and percentages of nurses' attitudes regarding cancer pain management pre and post education program $(\mathrm{N}=55)$.

\begin{tabular}{|c|c|c|c|c|c|}
\hline \multirow{2}{*}{ Nurses' Attitudes Items } & \multicolumn{2}{|c|}{ pre $(n=55)$} & \multicolumn{2}{|c|}{ post $(n=55)$} & \multirow{2}{*}{ P. Value } \\
\hline & no. & $\%$ & no. & $\%$ & \\
\hline Distraction of Patient from pain usually does not have pain & 18 & 32.7 & 48 & 87.3 & $0.001 * * *$ \\
\hline Respiratory depression withe stable dose of opioid & 38 & 69.1 & 49 & 89.1 & $0.010 *$ \\
\hline Use of in opioids with a history of substance abuse & 13 & 23.6 & 45 & 81.8 & $0.001 * * *$ \\
\hline Elderly patients cannot tolerate opioids & 17 & 30.9 & 49 & 89.1 & $0.001 * * *$ \\
\hline encourage Patients to endure the pain & 12 & 21.8 & 50 & 90.9 & $0.001 * * *$ \\
\hline Children under 11 years cannot reliably report pain. & 39 & 70.9 & 54 & 98.2 & $0.001 * * *$ \\
\hline Placebo is a useful test to determine reality of pain & 13 & 23.6 & 40 & 72.7 & $0.001 * * *$ \\
\hline judge of the intensity of the patient's pain & 25 & 45.5 & 53 & 96.4 & $0.001 * * *$ \\
\hline Pain development in alcohol/drug abuse & 18 & 32.7 & 48 & 87.3 & $0.001 * * *$ \\
\hline Mean \pm SD of Total attitudes score $($ Total $=9)$ & \multicolumn{2}{|c|}{$3.5 \pm 1.8$} & \multicolumn{2}{|c|}{$7.9 \pm 1.2$} & $\mathbf{P}<\mathbf{0 . 0 0 1} * * *$ \\
\hline
\end{tabular}

Chi-squire test to compare between percentages, paired t-test to compare between pre and post means

N.S: Non-significant $(P>0.05) \quad$ *: Significant $(P<0.05) \quad$ **: Moderate significant $(P<0.01)$

***: Highly significant $(P<0.001)$ 
Table (4): Nurses' practice in comparison between pre and post education program regarding cancer pain management at intensive care unit $(n=55)$.

\begin{tabular}{|c|c|c|c|c|c|}
\hline \multirow{2}{*}{ Items } & \multicolumn{2}{|c|}{ pre $(n=55)$} & \multicolumn{2}{|c|}{ post $(n=55)$} & \multirow{2}{*}{ P. Value } \\
\hline & no. & $\%$ & no. & $\%$ & \\
\hline \multicolumn{6}{|l|}{ Assessment of the patient } \\
\hline Assess general condition & 14 & 25.5 & 45 & 81.8 & $0.001 * * *$ \\
\hline \multicolumn{6}{|l|}{ Assess the patient pain } \\
\hline$\checkmark$ Location & 24 & 43.6 & 55 & 100.0 & $0.001 * * *$ \\
\hline$\checkmark \quad$ Duration & 1 & 1.8 & 54 & 98.2 & $0.001 * * *$ \\
\hline $\begin{array}{ll}\checkmark & \text { Intensity }\end{array}$ & 12 & 21.8 & 49 & 89.1 & $0.001 * * *$ \\
\hline $\begin{array}{ll}\checkmark & \text { Frequency }\end{array}$ & 0 & 0.0 & 34 & 61.8 & $0.001 * * *$ \\
\hline$\checkmark \quad$ Aggravating/ elevating factor & 0 & 0.0 & 30 & 54.5 & $0.001 * * *$ \\
\hline Check medication order & 40 & 72.2 & 55 & 100.0 & $0.001 * * *$ \\
\hline \multicolumn{6}{|l|}{ Procedure } \\
\hline Hands Washing & 27 & 49.1 & 45 & 81.8 & $0.001 * * *$ \\
\hline Identify patient & 49 & 89.1 & 54 & 98.2 & $0.050^{*}$ \\
\hline Administer pain- medication as order & 30 & 54.5 & 55 & 100.0 & $0.001 * * *$ \\
\hline \multicolumn{6}{|l|}{ non-pharmacological management } \\
\hline$\checkmark \quad$ Positioning & 17 & 30.9 & 50 & 90.9 & $0.001 * * *$ \\
\hline $\begin{array}{ll}\checkmark \text { Distraction } \\
\end{array}$ & 17 & 30.9 & 38 & 69.1 & $0.001 * * *$ \\
\hline$\checkmark \quad$ Relaxation & 10 & 18.2 & 30 & 54.5 & $0.001 * * *$ \\
\hline$\checkmark \quad$ Heat and cold & 14 & 25.5 & 44 & 80.0 & $0.001 * * *$ \\
\hline$\checkmark \quad$ Massage & 16 & 29.1 & 43 & 78.2 & $0.001 * * *$ \\
\hline$\checkmark \quad$ Emotional support & 15 & 27.3 & 49 & 89.1 & $0.001 * * *$ \\
\hline $\begin{array}{l}\text { Post Care } \\
\text { Assess of patient response } 1 / 2 \text { hour }\end{array}$ & 24 & 43.6 & 55 & 100.0 & $0.001 * * *$ \\
\hline Observed patient's nonverbal cue & 15 & 27.3 & 42 & 76.4 & $0.001 * * *$ \\
\hline Monitored for analgesic side effect & 12 & 21.8 & 51 & 92.7 & $0.001 * * *$ \\
\hline \multicolumn{6}{|l|}{ Documentation } \\
\hline Document of patient response & 4 & 7.3 & 39 & 70.9 & $0.001 * * *$ \\
\hline $\begin{array}{l}\text { Total mean score of nurses` practice } \\
\text { (total score }=20)\end{array}$ & \multicolumn{2}{|c|}{$6.2 \pm 3.2$} & \multicolumn{2}{|c|}{$16.7 \pm 2.3$} & $\mathbf{p}<0.001 * * *$ \\
\hline $\begin{array}{l}\text { Chi-squire test } \\
\text { N.S: Non significant }(\mathrm{P}>0.05) \\
* * \text { : Moderate significant }(\mathrm{P}<0.01)\end{array}$ & & $\begin{array}{l}*: \mathrm{Si} \\
* * *:\end{array}$ & $\begin{array}{l}\text { icant } \\
\text { hly si }\end{array}$ & $\begin{array}{l}.05) \\
\text { cant }(\mathrm{H}\end{array}$ & \\
\hline
\end{tabular}

Table (5): Relationship between Nurses' knowledge their practice regarding cancer pain management post implementation of education program $(n=55)$

\begin{tabular}{|c|c|c|c|c|c|}
\hline \multirow{2}{*}{ Practice } & \multicolumn{4}{|c|}{ Knowledge } & \multirow{2}{*}{ P. value } \\
\cline { 2 - 5 } & \multicolumn{2}{|c|}{ Satisfactory } & \multicolumn{2}{|c|}{ Unsatisfactory } & \multirow{2}{*}{} \\
\cline { 2 - 5 } & No. & $\mathbf{\%}$ & No. & \% & \\
\hline Adequate & 54 & 90.0 & 4 & 8.0 & \multirow{2}{*}{$<0.001 * * *$} \\
\hline Inadequate & 6 & 10.0 & 46 & 92.0 & \\
\hline
\end{tabular}

Chi-square test

Non-significant $(P>0.05)$

**: Moderate significant $(P<0.01)$ 
Table (1): Shows that; the nurse's age ranged from 20 to 45 years, the mean age of nurses was $(26.0 \pm$ $5.2)$, and Females were the majority $(87.3 \%)$. The nursing diploma was the highest proportion (54.5\%). $(49.1 \%)$ were less than one year of ICU experience and $(85.5 \%)$ of nurses not attending any previous education program about pain management.

Table (2): This table shows that there is a significant statistical difference $(\mathrm{P}<0.001)$ in nurses' knowledge related to pain assessment, patients variables, pharmacological and non-pharmacological items respectively in the comparison between pre and post education program. It was found also from this table that total $\mathrm{M} \pm \mathrm{SD}$ of Nurses' Knowledge related to same items was $(12.7+3.7)(27.0+3.3)$ respectively in pre and post education program.

Table (3): This table shows that there is a significant statistical difference $(\mathrm{P}<0.001)$ in nurses attitude related pain assessment, patients variables, pharmacological and non-pharmacological items in the comparison between pre and post education program. It was found also from this table that total $\mathrm{M} \pm \mathrm{SD}$ of Nurses' attitude related to pain assessment, patients variables, pharmacological and non-pharmacological items was $(3.5+1.8)(7.9+1.2))$ respectively in pre and post education program.

Table (4): This table shows that there is a significant statistical difference $(\mathrm{P}<0.001)$ in nurses' practice related to the assessment of the patient, procedure, post Care and documentation in the comparison between pre and post education program. It was found also from this table that total $\mathrm{M} \pm \mathrm{SD}$ of Nurses' practice items was $(6.2+3.2)(16.7+2.3)$ respectively in pre and post education program.

Table (5): This table shows that there is a significant statistically difference between nurse's knowledge and their practice scores post education program $(\mathrm{P}<0.001)$. It was found that there is $90 \%$ of satisfactory knowledge was with adequate practice on the other hand $92 \%$ of unsatisfactory were inadequate practice with a statistically significant difference.

\section{Discussion}

Cancer Pain is highlighted as a significant yet neglected problem among cancer patient and can lead to adverse effects. Activation of the sympathetic nervous system can increase the heart rate, blood pressure, and systemic vascular resistance, this increases workload and myocardial oxygen demand, and then myocardial ischemia or infarction may ensue. Metabolic responses to pain include an increase levels of catabolic hormones can lead to increased protein breakdown and impair wound healing. Unrelieved pain can have significant psychological consequences such as impairment of sleeping. Last, but certainly not least, is the possible development of chronic pain, from the pain state. (Mowat \& Johnson, 2013)

The results of the present study showed that the majority of nurses were aged from 20 - 45 years, with a mean $26.0+5.2$, the majority of nurses were female and married. More than half of nurses had a diploma. Slightly less than half of nurses (49.1) had less than one year of ICU experience. The few years of unit experience could be explained by rotating of nurses from one unit to another within the hospital. The current study revealed that the majority of the nurses did not receive training programs about the pain management; it could be due to limited attention to nurses' continuing education or training programs especially about pain management. Approximately the same finding was indicated by (Bernardi et al., 2007) who found that majority of nurses did not receive training programs about pain management. The quality of pain management depends on the knowledge, attitudes and skills of those who provide the treatment. Nurses play a crucial role in this process. They often act as mediators between the doctor and the patient and serve as the main observer of pain and discomfort in the patient. However, nurses need to have systematic training in painrelated topics to enhance their knowledge and attitudes to manage pain (De Rond et al., 2008)

Concerning the effect of the present education program that there were statistically significant differences between nurses' knowledge and attitudes before and after the program, the current study revealed that most of the nurses had unsatisfactory level of knowledge and attitudes before implementation of education program regarding pain assessment, patient variables, pharmacology and non-pharmacological knowledge and attitudes related to the management of cancer pain, this can be explained by the fact that nurses may receive limited continues education program related to pain.

Regarding the Nurses' knowledge and attitudes about pain assessment, in the present study analysis of the items which ascertained knowledge and attitudes regarding the assessment of pain were generally not encouraging before the program. They improved in studied nurses immediately post education program. These results are in agreement with (Patiraki, 2006) that looked at the effects of an educational intervention on nursing staff with regard to the nurses' knowledge and attitudes of cancer pain management. The tool used was the knowledge and attitudes survey regarding pain (KASRP) and was administered before and after the intervention. Preintervention scores showed that these nurses had many limitations with regard to pain assessment and 
management. Post-intervention scores showed a significant effect on their knowledge and attitudes. Concerning nurses' knowledge and attitudes about pain related patient variables the current study shows that the majority of the nurses had poor knowledge base and were below acceptable level in items which evaluated knowledge and attitudes with regard to specific patient variables before the program, after the program the nurses' shows significant improvement in nursing knowledge and attitudes. This finding was congruent with (Wang \& Tsai, 2010) who found that the educational program improved nurses' knowledge and attitudes toward patient variables of pain perception and the various influences and concepts which may alter pain interpretation and expression.

Regarding knowledge and attitudes of pharmacological and non- pharmacological approaches to pain management, a considerable number of items on the tool (KASRP) are pharmacology based, which are vital in the management of pain. This confirms the necessity for nurses to possess a good knowledge base in the area of pharmacological management of pain. However, in the current study, before the program the nurses showed widespread knowledge deficits and extensive misconceptions in numerous areas of basic pharmacological knowledge which related to: drug action, routes of administration, equianalgesic dosing, drug uses, untoward side effects of opioid analgesics, addiction, risk of respiratory depression, and selection of drug dosages. The results were consistent with (Kaki et al., 2007) who conducted an survey seeking to determine levels of nurses' knowledge in pain management in Western Saudi Arabia to assist in determining educational needs, and found that there were misconceptions and a lack of knowledge about addiction, dosing regimens, preferred route of administration, determination of pain intensity, and risk related to opioids such as sedation and respiratory depression thus leading to the under-treatment of pain.

Nurses' knowledge and attitudes improved immediately post-education program in relation to the management of pain, addiction, dosing regimens, preferred route of administration, risk related to opioids such as sedation and respiratory depression. This improvement might be related to the fact that majority of them are young and have a strong desire to learn new knowledge. The present finding is in agreement with (Qadire \& Khalaileh, 2014) using the same tool (KASRP) was conducted in Jordan entitled as (effectiveness of the educational intervention on Jordanian nurses' knowledge and attitude regarding pain management. This study revealed that there is a significant improvement in nurses knowledge and attitudes after education program in all items in the area of pharmacological aspects of pain and its management.

The present study demonstrated that the educational program on pain management was effective in improving nurses' knowledge and attitudes toward cancer pain management. The average number of correct answers on the questions significantly improved after the program, in the same line nurses' knowledge and an attitude regarding hospitalized patients with pain was explored by (Jarrett et al., 2013). The study was conducted to determine nurses' knowledge and attitudes regarding pain management prior to an educational program, and immediately following the educational program. The study took place in care hospital. The Knowledge and Attitudes Survey Regarding Pain was the instrument utilized to obtain the data. Findings revealed the post-test scores were significantly higher following pain management education than pre-test scores.

As previously described, the results from the data collected were positive because an increase in scores was noted between the pretest and posttest. The findings in this research revealed successful improvement in the nurses' knowledge and attitudes regarding cancer pain management. Therefore, A pain management education program is needed for nurses in critical care units and should provide more educational opportunities to ensure up-to-date knowledge and attitudes in delivering patient care.

The findings of the present study showed the inadequate level of practice scores in all items preimplementation of an education program about cancer pain management. The majority of nurses didn't perform adequate care and didn't do adequate assessment and management for the patients' pain. Inadequate level of practice can be explained that an only14.5\% of participant had achieved training program on pain topic that has proven helpful in increasing skill in the area of pain management. Another possible reason revealed that nurses in the institute do not provide active hands-on practice for the direct care of patients. The nurses usually manage patients' pain according to doctor order.

After implementation of the education program, nurses had better practice in pain assessment than before attending the pain education program, nurses documented improvement with special attention to patients' pain intensity, pain location, duration, frequency and significantly increased pain assessment practice. This finding indicated that skills can be easily improved, especially if linked with their relevant scientific base of knowledge. In accordance with our study (Ger et al., 2004) nurses in this study demonstrated an improvement in pain assessment practice; the percentage of nurses who 
correctly assess patients' pain intensity, duration, location increased significantly after the education program, the education program did significantly improve the pain assessment frequency and quality.

Regarding non-pharmacological interventions, the nurses show low percent concerning the use of some non-pharmacological interventions in the preeducation program such as positioning, distraction, massage, relaxation and emotional support. The low percent of non-pharmacological intervention was used in the pre-education program may be a reflection of the lack of knowledge and clinical practice to utilize these techniques as options in cancer pain management. Another possible reason that may be reflecting on the limited use of these in critical care units, which include workload, staffing levels and poor attitude of some nursing staff.

After implementation of education program, it was noted that the majority of nurses show significant improvement and realize the important role of nonpharmacological interventions in reducing of cancer pain as part of, not instead of, all pain management strategies. This is supported by (Matthews \& Malcolm, 2007). They found that nonpharmacological interventions are very effective for combining the treatment of pain.

Regarding Impact of an education program on pain documentation, there were statically significant improvements after education program this means that nurses recognized the importance of documentation as an important indicator for their pain management practices. Nurses usually documented about patient response to the medication and symptoms associated with pain and side effects of pain medication. in this respect, this finding agrees with (McNamara et al., 2012) who confirmed the effectiveness of the educational programs in improving nursing documentation practices

The pain education program proved to be effective in improving nurses' pain assessment practices. The majority of respondents changed their Practice based on the information they had received. The current study revealed a great improvement in the practice score levels obtained by nurses after implementation of education program in all items. This has been concluded by the presence of significant differences between results of pre and post education program. In agreement with our findings (Zhang et al., 2008) examined the effectiveness of education program on nurses' pain knowledge, attitudes and pain assessment practices in China. The results demonstrated significant improvements after completion of the program and found that education program about pain contributes to nurses' pain knowledge, attitudes and practice in a systematic manner.

As regarding relation between nurses' knowledge and practice the present study finding revealed that there was highly statistical significant relation observed during the post-test. This finding is in agreement with (Lin et al., 2008) who stated that a highly statistical significant relation between participants' scores of knowledge and practice in post-test. This strong relation between nurses' knowledge and practice is highly expectable; however, the effective establishment of pain management is often hindered by a lack of knowledge, basic knowledge about pain management is essential for nursing practice.

\section{Conclusions}

It was concluded that nurses in intensive care unit at South Egypt Cancer Institute in Assiut University were lacking the necessary basic knowledge and attitudes and inadequate practice in the areas of addiction, scheduling of analgesics, the pharmacological and non-pharmacological treatment of cancer pain and in the assessment of pain. In addition, this study shows that education program about cancer pain management could improve nurses' knowledge, attitudes and practice regarding pain management. However, the sustainability of the change needs to be further investigated. Furthermore, regular teaching sessions within clinical settings would also hone pain management skill and knowledge.

\section{Recommendations}

Based on the finding of this study, following recommendations were made

1- Regular updates about pain management should be provided for all nurses of ICU.

2- A variety of teaching strategies should be used to teach pain management including teaching rounds, case studies, seminars and scientific journals to make nurses awareness about pain management.

3- Nurses should be equipped with the necessary knowledge and skills to aid in the provision of services to the patients and also should be encouraged to develop the right professional attitudes to enhance their work.

4- Similar studies on a larger sample acquired from different geographical areas in Egypt should be done to achieve more generalizable results.

5- Nurses should be encouraged to use pain measurement scale to assess the pain. 


\section{References}

1. Elumelu, T., Adenipekun, A., Eriba, L., \& Akinlade, B., (2014): Knowledge of cancer pain management among nurses in a Nigerian tertiary health institution. Journal of Nursing Education and Practice, 4(4), pp.74-80.

2. Borglin, G., Gustafsson, M., \& Krona, H., (2011): A theory-based educational intervention targeting nurses' attitudes and knowledge concerning cancer-related pain management: a study protocol of a quasi-experimental design. BMC health services research, 11(1), p.233.

3. Turk, D.C. \& Okifuji, A., (2010): Pain terms and taxonomies of pain 4th ed., Philadelphia: Lippincott, Williams, and Wilkins.

4. Abdalrahim, M., Majali, S., Stomberg, M., Bergbom, I., (2011) The effect of postoperative pain management program on improving nurses' knowledge and attitudes toward pain. Nurse Edu. Pract, 11 (4), pp.250-255.

5. Namukwaya, E., Leng, M., Downing, J., \& Katabira, E., (2011) Cancer pain management in resource-limited settings: a practice review. Pain Research and Treatment, pp.393-404.

6. Smeltzer, S., Bare, P., Hinkle, J., \& Cheever, K., (2012): Brunner and Suddarth's Textbook of Medical-Surgical Nursing Textbook of MedicalSurgical Nursing 12th ed. Philadelphia: Lippincott Williams \& Wilkins.

7. Jastrzab, G., Fairbrother, G., Kerr, S., \& Mcinerney, M., (2004): Profiling the "painaware" nurse: acute care nurses' attitudes and knowledge concerning adult pain management. Australian Journal of Advanced Nursing, 21(2), pp.27-32.

8. Mathew, P., Mathew, J., \& Singhi, S., (2011): Knowledge, attitude, and practice of pediatric critical care nurses towards pain: a survey in a developing country setting. Journal of postgraduate medicine, 57(3), pp.196-200.

9. Ferell, B., \& Mccaffery, M., (2012) Knowledge and attitude Survey regarding pain. Retrieved from http://prc.coh.

10. Mowat, I., \& Johnson, D., (2013) Acute pain management part 2 assessment and management. Anaesthesia tutorial of the week, 259, pp.1-10.

11. Bernardi, M., Catania, G., Lambert, A., Tridello, G. \& Luzzani, M., (2007): Knowledge and attitudes about cancer pain management: A national survey of Italian oncology nurses. European Journal of Oncology Nursing, 119(3), pp.272-279.

12. De Rond, M., de Wit, R., van Dam, F., van Campen, B., den Hartog, Y., \& Klievink, R., (2008): A pain monitoring program for nurses: effects on nurses' pain knowledge and attitude. Journal of Pain and Symptom Management, 19(6), pp 457-467.

13. Patiraki, E., Papathanassoglou, E., Tafas, C., Akarepi, V., Katsaragakis, S., Kampitsi, A., \& Lem- onidou, C., (2006) A randomized controlled trial of an educational intervention on Hellenic nursing staff's knowledge and attitudes on cancer pain management. European Journal of Oncology Nursing, 10(5), pp337-352.

14. Wang, H., \& Tsai, Y., (2010): Nurses' knowledge and barriers regarding pain management in intensive care units. Journal of Clinical Nursing, 19(21), pp.3188- 3196.

15. Kaki, A., Daghistani, M., \& Msabeh, A., (2007) Pain management in Western Saudi Arabia. Saudi Medical Journal, 30(2), pp.279283

16. Qadire, M., \& Khalaileh, M., (2014): The effectiveness of Educational Intervention on Jordanian Nurses' Knowledge and Attitude Regarding Pain Management. British Journal of Medicine \& Medical Research, 4(7), pp.14601472.

17. Jarrett, A., Church, T., Shackelford, J., Lofton, A., \& Fancher, Gonzales, K., (2013): Nurses 'Knowledge and Attitudes about Pain in Hospitalized Patients. Clinical Nurse Specialist, 27(2), pp.81-87

18. Ger, L., Chang, C., Ho, S., Lee, M., Chiang, H., Chao, C., Wang, S., (2004): Effects of a continuing education program on nurses' practices of cancer pain assessment and their acceptance of patients' pain report. Journal of Pain and Symptom Management, 27(1), pp.6171.

19. Matthews, E., \& Malcolm, C., (2007): Nurses' knowledge and attitudes in pain management practice. British Journal of Nursing, 16(3), pp.174-179.

20. McNamara, M., Harmon, D., \& Saunders, J., (2012): Effect of education on knowledge, skills and attitudes around pain. British Journal of Nursing, 21(16), pp.958-964.

21. Zhang, C., Hsu, L., Zou, B., Li, J., Wang, H., \& Huang, J., (2008) Effects of a pain education program on nurses' pain knowledge, attitudes and pain assessment practices in China. Journal of Pain and Symptom Management, 36(6), pp.61627.

22. Lin, P., Chiang, H., Chiang, T., Chen, C., (2008): Pain management: evaluating the effectiveness of an educational program for surgical nursing staff. Journal of Clinical Nursing, 17 (15), pp.2032-2041. 